\title{
NO REFERENCE QUALITY OF HAZY IMAGES DEPENDING ON TRANSMISSION COMPONENT ESTIMATION
}

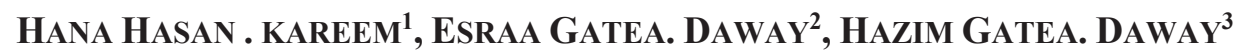 \\ ${ }^{1}$ Department of Physics, College of Education, \\ Mustansiriyah University, Baghdad, Iraq. \\ ${ }^{2}$ Department of Medical Instrumentation Techniques Engineering, \\ Bilad AlRafidain University College, Baghdad, Iraq. \\ ${ }^{3}$ Department of Physics, College of Science, \\ Mustansiriyah University, Baghdad, Iraq.
}

*Corresponding author: hazimdo@uomustansiriyah.edu.iq

(Received: $6^{\text {th }}$ October 2018; Accepted: $30^{\text {th }}$ July 2019; Published on-line: $2^{\text {nd }}$ December 2019)

\begin{abstract}
The research aim is to measure the quality of hazy images using a noreference scale based on the Transmission Component and Wavelet Transform (TCWT) by calculating the histogram in the High and Low (HL) component. The system is designed to capture several images at different levels of distortion from little to medium to high and the quality is studied in the transmission component. This measure is compared with the other no-reference measurements as a Haze Distribution Map based Haze Assessment (HDMHA) and Entropy by calculating the correlation coefficient between the no reference measurements and the reference scale Universal Quality Index (UQI). The results show that the proposed algorithm TCWT is a good measure of the quality of hazy images.
\end{abstract}

\begin{abstract}
ABSTRAK: Kajian ini bertujuan bagi mengukur kualiti imej berjerebu dengan menggunakan skala tiada-rujukan berdasarkan Komponen Transmisi dan Penukaran Signal Gelombang (TCWT) dengan mengira komponen Tinggi dan Rendah (HL) histogram. Sistem ini dicipta bagi mengumpul imej pada tahap berbeza dari takat selerakan paling rendah kepada paling tinggi dan kualiti imej diselidik dalam komponen transmisi. Ukuran ini dibandingkan dengan ukuran tiada-rujukan lain sebagai Peta Selerak Berjerebu (UQI). Keputusan menunjukkan algoritma kualiti imej berjerebu TCWT yang dicadangkan adalah berkualiti baik..
\end{abstract}

KEYWORDS: no reference quality; wavelet transform; hazy images; transmission

\section{INTRODUCTION}

The atmosphere reacts to light due to the atmosphere's composition under steady conditions. The atmosphere includes a variety of different molecules and small types of suspended particles, called aerosols [1]. As such, the primary problem presented is the distortion of aerial imaging by these particles. Aerosols, by definition, are very fine liquid or solid particles suspended (in the air) in the atmosphere with a very low fall speed. Their size mostly lies between $10^{-2} \mathrm{~m}$ and $100 \mu \mathrm{m}$. Furthermore, dust, fog, haze, drizzle, smoke, rain, and snow are some of the examples of aerosols [2]. The majority of aerial images have been taken under bad conditions and thus, need a quality scale. The quality scale provides a pointer on the degree of deformation as well as the degree of improvement. Correspondingly, the image quality assessment is a hot spot in the field of image processing. 
In the classified Image Quality Assessment (IQA) [3], the two main categories are fidelity and intelligibility of the image. The fidelity is described as deviation level between the evaluated image and a standard image. The intelligibility is the image's ability to provide related information to people or a computer. The image quality measure can be estimated by quantitative measurement of the combination of the two classes. Currently, IQA is segregated into (i) the subjective estimation method, and (ii) the objective estimation method. The previous method uses people's subjective sense in order to evaluate the quality level of the images while the latter simulates perception technique of Human Visual System (HVS) in order to measure it. Several corresponding existing approaches are known as FullReference (FR), Reduced-Reference (RR), and No-Reference (NR).

Among these methods, the Full Reference method is based on HVS [4,5], Structural Similarity Measurement (SSIM) [6] , and Universal Quality Index (UQI) [7], which were developed a long time ago and were subsequently applied in several areas. In general, the No Reference IQA method can be divided into two categories [8]: (i) Algorithms developed for specific types of distortion, such as blur [9], JPEG and JPEG2000 compression [10,11], and noise [12] and (ii) Non-distortion specific algorithms. Moorthy and Bovik [13] proposed a two-step framework (BIQI) for No Reference IQA based on natural scene statistics, which did not require any prior knowledge of the distorting process, once trained, as evidenced by Tang et al. [14]. Another research [15] proposed the method to determine No Reference image quality by depending on the entropy (ENT) of the first derivative of the lightness. Furthermore, an evaluation of the histogram of the edge regions in [16] suggested that the No Reference measure, which depends on the Range Channel (RGB) of the image, is defined and the Haze Distribution Map (HDM) that is extracted from the hazy image and then the Haze Assessment Metric HDM-based Haze Assessment (HDMHA) is designed according to the HDM using Google earth maps.

\section{PROPOSED ALGORITHM TO MEASURE THE QUALITY OF THE HAZY IMAGES}

In real visual systems, the effects of the haze in the scene rely on the haze density level and coverage area of the haze. Increasing the density of the haze and increasing the area covered by haze, leads to an increased distortion in the resulting image. The proposed method, thus, depends on the estimation the transmittance components from the image. Following which, a wavelet transform of this component is calculated. The wavelet transform is further analyzed by calculating the histogram.

\subsection{Estimating the Transmission}

In a single image distorted by haze, an optical transmission (T) can only be evaluated depending on the hazy image [17-19]. In the calculation, possibly, an Atmospheric Light (A) value may be given. Thus, by superimposition, the transmission in a local patch $R(x)$ is constant. We denote the patch's transmission $\hat{\mathrm{t}}(\mathrm{x})$ to have the min value in the local patch $\mathrm{R}(\mathrm{x})$ on the haze image. The transmission is, thereby, given by [20]:

$$
\hat{\mathrm{t}}(\mathrm{x})=1-\mathrm{d}_{\circ} \min _{\mathrm{c}}\left(\min _{\mathrm{y} \in \mathrm{R}(\mathrm{x})}\left(\frac{\mathrm{I}^{\mathrm{c}}(\mathrm{y})}{\mathrm{A}^{\mathrm{c}}}\right)\right)
$$

In this equation, the term $\min _{\mathrm{y} \in \mathrm{R}(\mathrm{x})}\left(\frac{\mathrm{I}^{\mathrm{c}}(\mathrm{y})}{\mathrm{A}^{\mathrm{c}}}\right)$ is dark channel of the haze image. An optional is to keep a very small amount of haze for distant objects, depending on the constant $\mathrm{d}_{\circ}\left(0<\mathrm{d}_{\circ} \leq 1\right)$. In this study, we have used $\mathrm{d}_{\circ}=0.95, \mathrm{~A}^{\mathrm{c}}=0.62$ as in [18]. Figure 1 illustrates the transmission for the flower images using equation (1). 


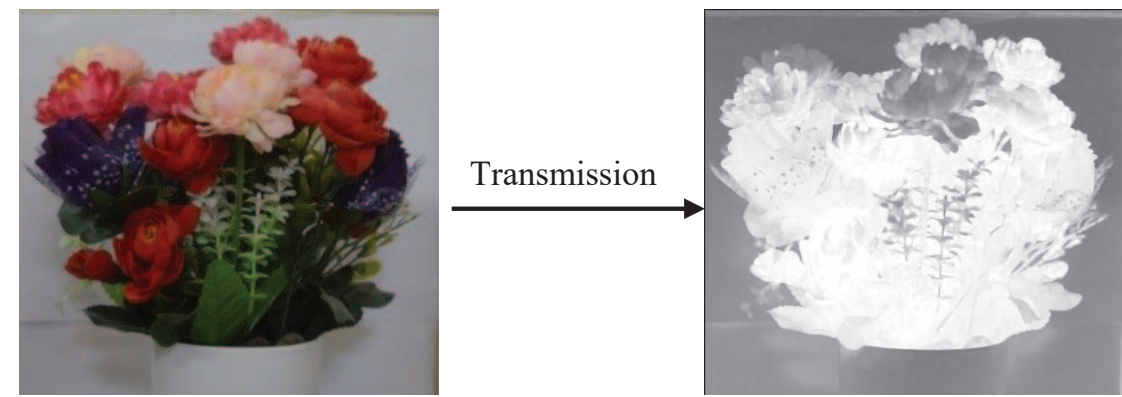

Fig. 1: The flower image and its transmission.

\subsection{Histogram of the HL Component in the Wavelet Transform}

Wavelet transforms are significantly beneficial tools for image processing; they have been used extensively in procedures involving image processing, data compression, and signal processing. Figure 2 illustrates the wavelet transform for one level decomposition using a haar transform [21]. Wherein, the quality scale is based on a conversion of transmission image rather than the original image, and the histogram is calculated for the HL component. Figure 3 shows this transform for the original transmission image (free haze) and its histogram of the HL component.

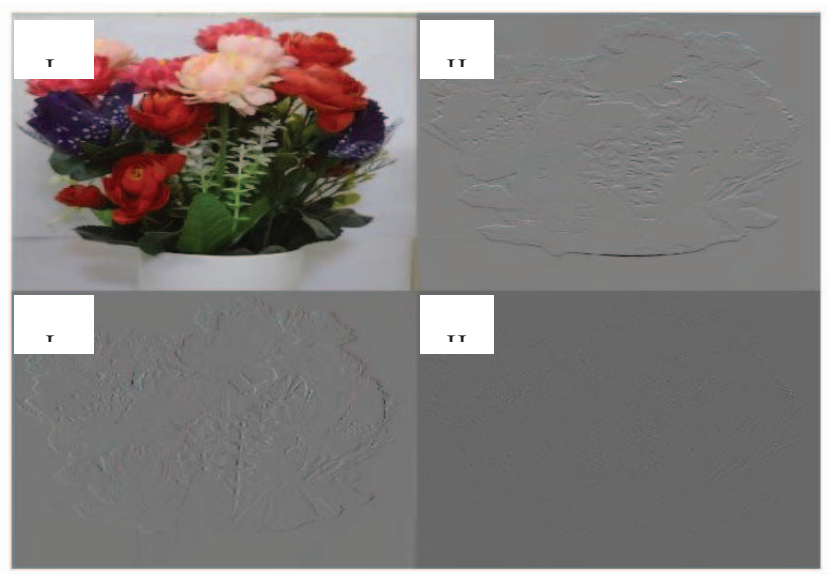

Fig. 2: The wavelet transform for the flower image and its components.
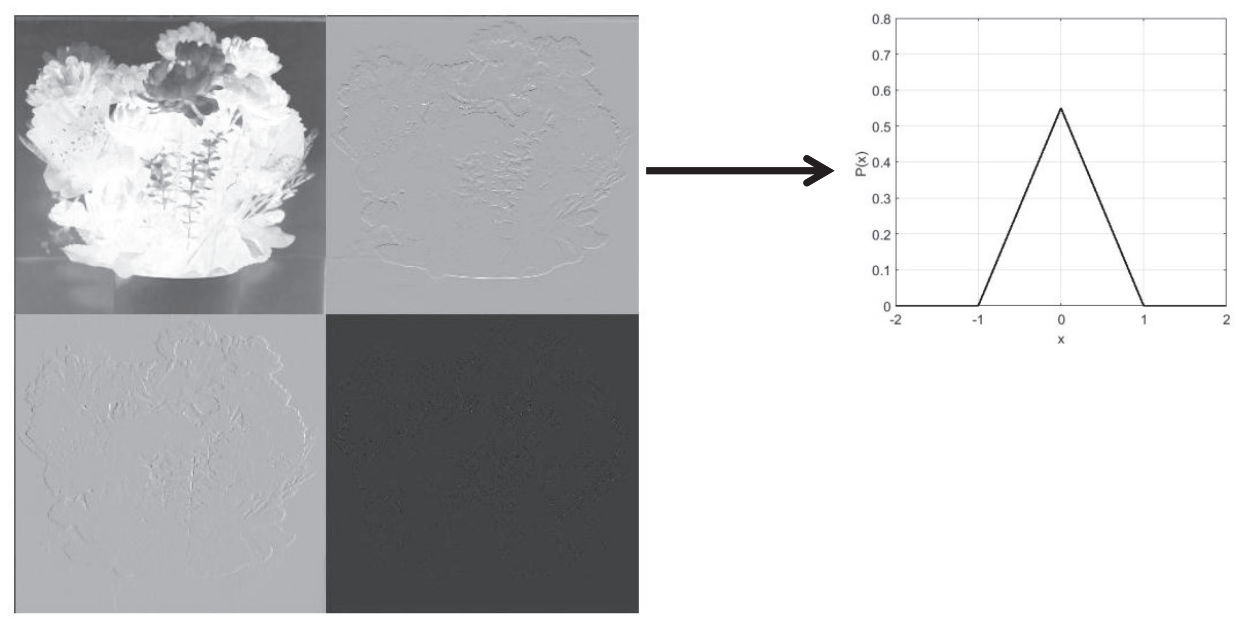

Fig. 3: The wavelet transform for the transmission of the flower image with free haze and histogram of the HL component. 
Figure 4 illustrates this transform for the transmission image (for haze images) and its histogram of the HL component. In the histogram distributions, we can see that the maximum value is inversely proportional to the haze ratio in the image, where this feature can be investigated in the creation of a blind-reference quality measure by using:

$$
Q_{-} T C W T=1 / \max (\text { hist_HL) }
$$

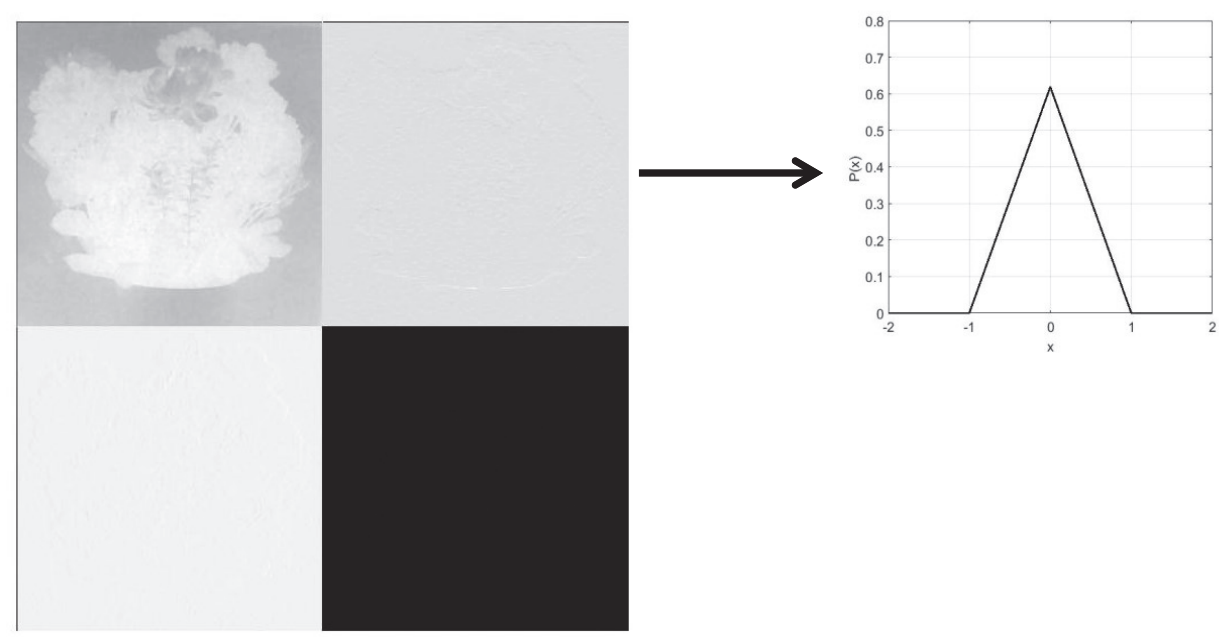

Fig. 4: The wavelet transform for the transmission flower image with distortion by haze and histogram of a HL component.

The increase in the haze ratio leads to a decrease in quality by reducing the Q_TCWT factor while an increase in quality, leads to increased Q_TCWT. The TCWT algorithm can be performed with the following procedure:

1. Input hazy images $\operatorname{Ih}(\mathrm{x}, \mathrm{y})$.

2. Estimate the Transmission using Eq. (1) to get $\mathrm{Th}(\mathrm{x}, \mathrm{y})$.

3. Transform $\mathrm{Th}(\mathrm{x}, \mathrm{y})$ image by finding the wavelet transform for one level.

4. Estimate the HL component from the wavelet transform to get ThHL(x,y).

5. Calculate the histogram for $\operatorname{ThHL}(\mathrm{x}, \mathrm{y})$.

6. Compute the quality based on TCWT by using Eq. (2).

\section{UNIVERSAL QUALITY INDEX}

Instead of using traditional error summation measurements, we can use a method referred to as Universal Quality Index (UQI) to model any image distortion. [7]:

$$
\mathrm{UQI}=\frac{4 \overline{\mathrm{I}} \overline{\mathrm{I}}_{\mathrm{n}} \sigma_{\mathrm{II}}}{\left(\overline{\mathrm{I}}^{2}+\overline{\mathrm{I}}_{\mathrm{n}}^{2}\right)\left({\sigma_{\mathrm{I}}}^{2}+{\sigma_{\mathrm{II}_{\mathrm{n}}}}^{2}\right)}
$$

where $\bar{I}$ and $\overline{\mathrm{I}}_{\mathrm{n}}$ are the mean of the original and processing (or hazy) images, $\sigma_{\mathrm{I}}$ and $\sigma_{\mathrm{I}_{\mathrm{n}}}$ are the standard deviation between the original and processed (or noisy) images. $\sigma_{\mathrm{II}_{\mathrm{n}}}$ is the covariance, which can be defined as[7]:

$$
\sigma_{I_{\mathrm{n}}}=\frac{1}{\mathrm{~N}-1} \sum_{\mathrm{i}=1}^{\mathrm{N}}(\mathrm{I}-\overline{\mathrm{I}})\left(\mathrm{I}_{\mathrm{n}}-\overline{\mathrm{I}}_{\mathrm{n}}\right)
$$




$$
\mathrm{UQI}=\left(\frac{\sigma_{\mathrm{II}}}{\sigma_{\mathrm{I}_{\mathrm{n}}} \sigma_{\mathrm{I}}}\right)\left(\frac{2 \overline{\mathrm{I}} \overline{\mathrm{I}}_{\mathrm{n}}}{\left(\overline{\mathrm{I}}^{2}+\overline{\mathrm{I}}_{\mathrm{n}}^{2}\right)}\right)\left(\frac{2 \sigma_{\mathrm{I}_{\mathrm{n}}} \sigma_{\mathrm{I}}}{\sigma_{\mathrm{I}}^{2}+\sigma_{\mathrm{I}_{\mathrm{n}}}^{2}}\right)
$$

\section{RESULTS AND DISCUSSION}

In this study, we have designed a system to measure the level of the haze (dust form), which distorts the color image. Figure 5 shows the complete system, which contains a firm glass box, HeNe laser, fan, lux meter, camera stand, and camera. Dust is raised by the fan in the box, whereby the lux meter immediately measures the laser intensity. While more dust is added into the box, the dust in the bottom of the box is stirred. After a short span of time, the dust settles at the bottom of the box, and once the dust has settled, images are taken from the camera a second time. The lux meter reads the intensity of the laser light, which decreases as the intensity of dust increases and increases according to the reduced density at the same time as the camera captures the images. During the course of the experiment, in the current study, 39 images were taken, each group contained 13 images (distorted from high to low by hazy) with size (1068*1040 pixel). Subsequently, all the images were processed using a MATLAB program version 2013a.

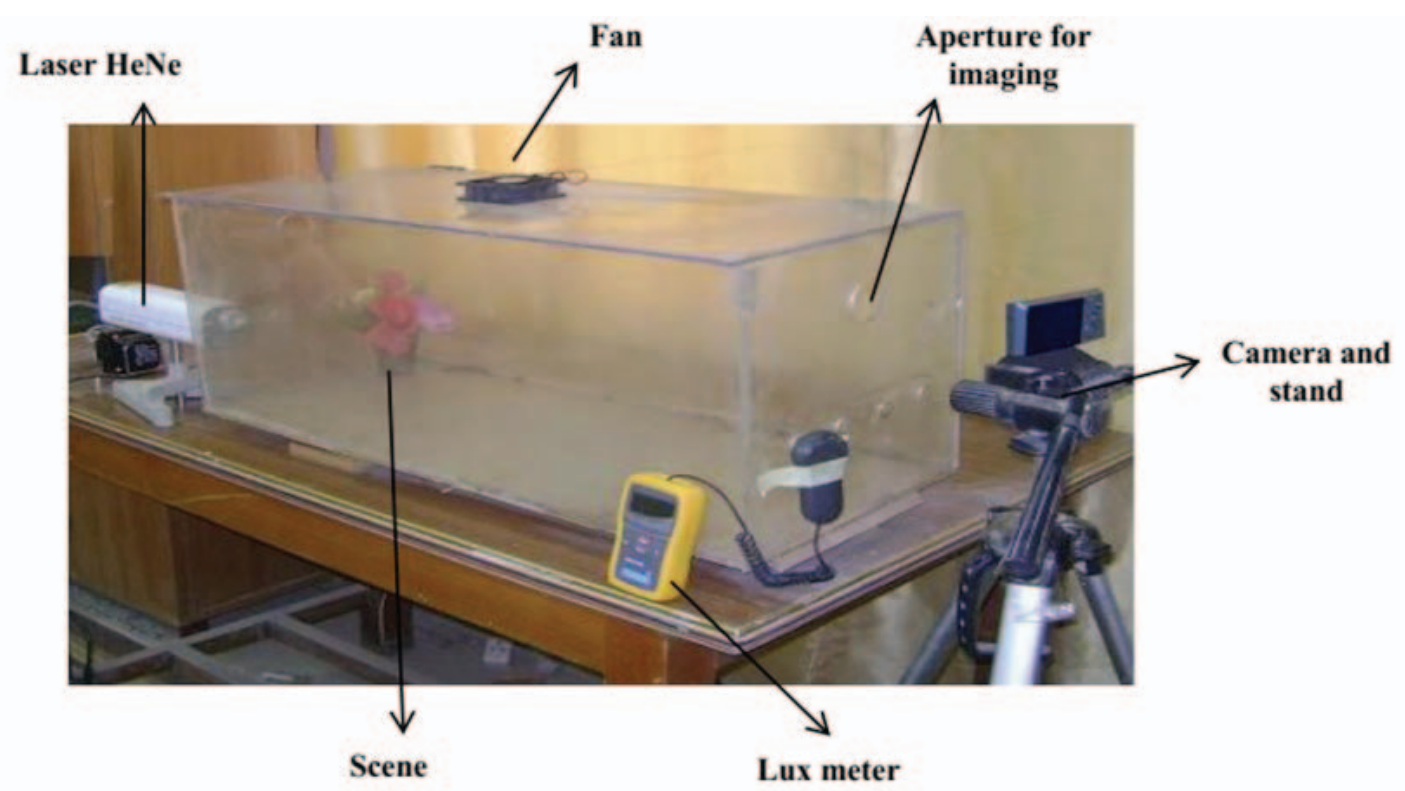

Fig. 5: The system used to capture the hazy image with deformation levels from high to low.

In this research, the reference measure values (UQI) of the hazy images was calculated as well as no-reference measures (ENT, HDMHS, and TCWT) were computed for all measurements. These relationships are illustrated in Figs. 7, 8 and 9 for all the group images. Note, as apparent from all these relationships, the non-reference measure TCWT is closer to reference measure UQI, followed by HDMHS then ENT. This behaviour is reflected in the correlation coefficients between the reference scale and non-reference measures. Note that the greatest value of the correlation is 0.9864 because it is close to one for the TCWT as shown in Table 1, and then correlation coefficients are lower in HDMHS and ENT. 

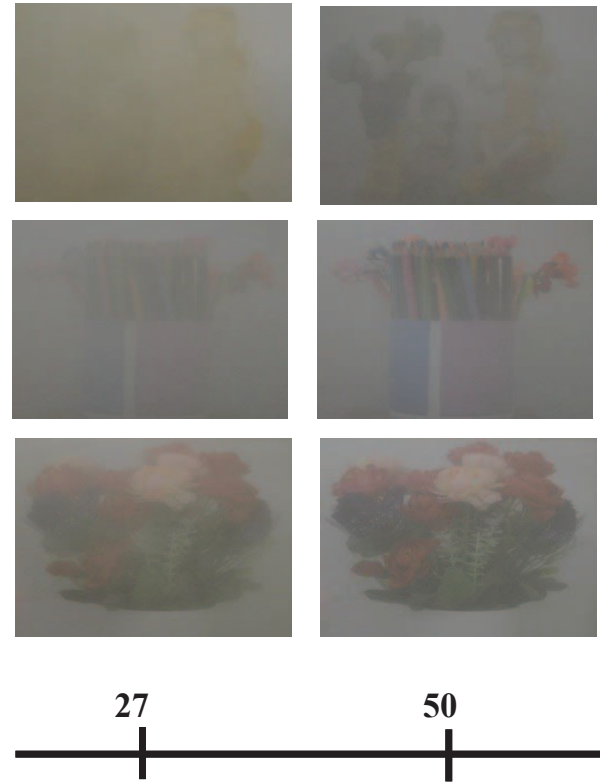
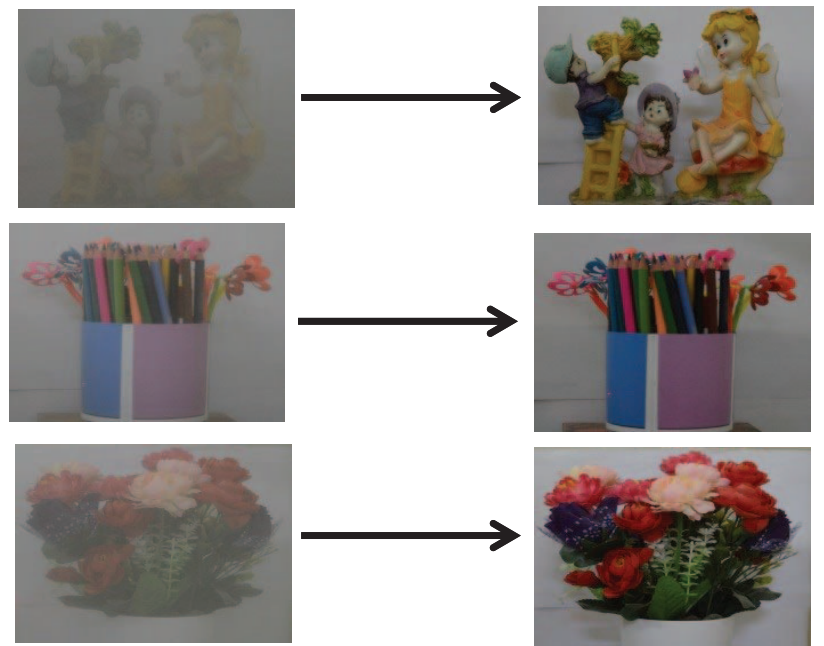

129
203 (Lux)

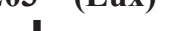

Fig. 6: The first row represents some images in the first group, i.e., artwork images, the second row represents the second group, i.e., the pens images and the third row represents the second group, i.e., the flower images. All images were taken in about 27 to 203 lux.
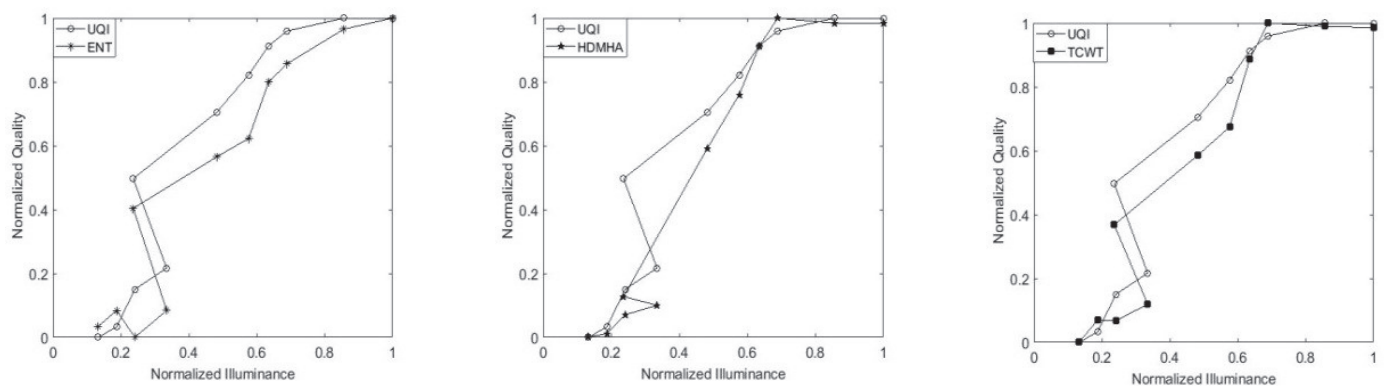

Fig.7: The relationship between normalized quality measurements and normalized illuminance for the first group images.
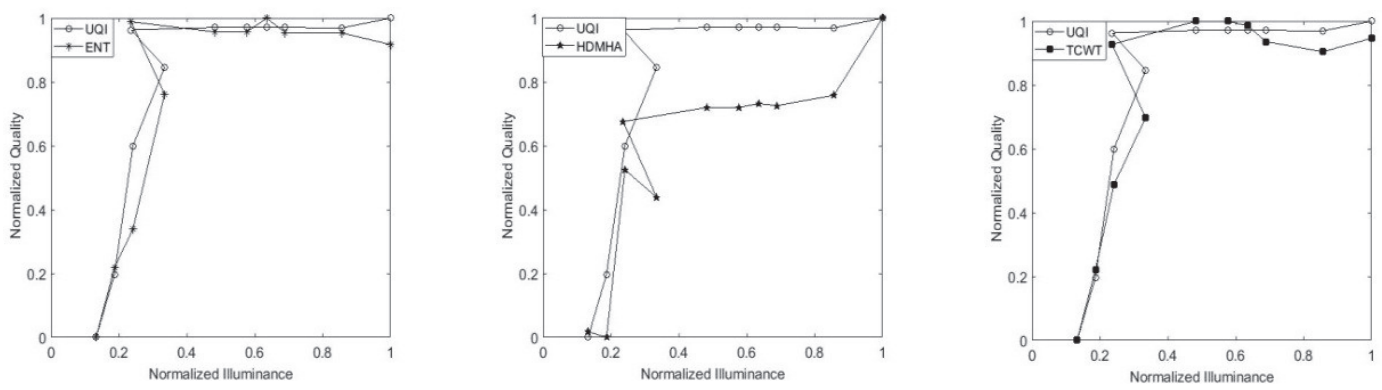

Fig. 8: The relationship between normalized quality measurements and normalized illuminance for the second group images. 

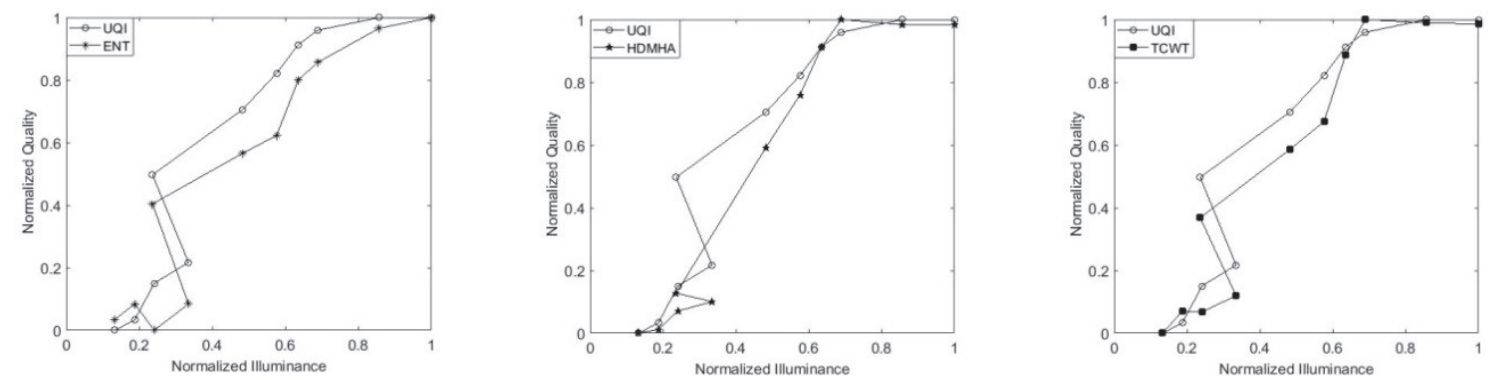

Fig. 9: The relationship between normalized quality measurements and normalized illuminance for the third group images.

Table 1: Correlation Coefficient between the reference measure (UQI) and nonreference measure for all image groups

\begin{tabular}{cccc}
\hline Method & First G. & Second G. & Third G. \\
\hline$T C W T$ & 0.9864 & 0.9857 & 0.9864 \\
$H D M H W$ & 0.9798 & 0.9735 & 0.9798 \\
$E N T$ & 0.9686 & 0.9339 & 0.9686 \\
\hline
\end{tabular}

\section{CONCLUSION}

In this research a non-reference scale TCWT was proposed to measure the quality of hazy images based on Transmission. This measure is compared with the HDMHW and ENT measurements by calculating the correlation coefficient. Through the analysis of the results, we note that the TCWT is a suitable performance metric for measuring the quality of hazy images and a good proportion if it is comparable with other non-reference measures in the ENT and HDMHW, because the proposed method has higher correlation (0.9864) compared to other methods.

\section{REFERENCES}

[1] Aber, J. S., Marzolff, I., \& Ries, J. B. (2010). Small-format aerial photography. Boston: Elsevier. 266.

[2] Murphy, B. L., and Morrison, R. D. (2002). Introduction to Environ-mental Forensics . San Diego, CA: Academic Press.

[3] Abdou IE, Dusaussoy NJ. (1986) Survey of image quality measurements. Paper presented at Proceedings of 1986 ACM Fall joint computer conference, IEEE Computer Society Press. pp71-78.

[4] Yu Z, Wu HR, Winkler S, Chen T. (2002) Vision-model-based impairment metric to evaluate blocking artifacts in digital video. Proceedings of the IEEE, 90(1): 154-169.

[5] Nill NB, Bouzas B. (1992) Objective image quality measure derived from digital image power spectra. Optical Engineering, 31(4): 813-826.

[6] Wang Z, Bovik AC, Sheikh HR, Simoncelli EP. (2004) Image quality assessment: from error visibility to structural similarity. IEEE Transactions on Image Processing, 13(4): 600-612.

[7] Wang Z, Bovik AC. (2002) A universal image quality index. IEEE Signal Processing Letters, 9(3): 81-84.

[8] Lu Y, Xie F, Wu Y, Jiang Z, Meng R. (2015) No reference uneven illumination assessment for dermoscopy images. IEEE Signal Processing Letters, 22(5): 534-538. 
[9] Cao Z, Wei Z, Zhang G. (2014) A no-reference sharpness metric based on the notion of relative blur for Gaussian blurred image. Journal of Visual Communication and Image Representation, 25(7): 1763-1773.

[10] Corchs S, Gasparini F, Schettini R. (2014) No reference image quality classification for JPEG-distorted images. Digital Signal Processing, 30: 86-100.

[11] Liang L, Wang S, Chen J, Ma S, Zhao D, Gao W. (2010) No-reference perceptual image quality metric using gradient profiles for JPEG2000. Signal Processing: Image Communication, 25(7): 502-516.

[12] Liu M, Zhai G, Zhang Z, Sun Y, Gu K, Yang X. (2014) Blind image quality assessment for noise, paper presented at Broadband Multimedia Systems and Broadcasting (BMSB), 2014 IEEE International Symposium on, IEEE, 1-5.

[13] Moorthy AK, Bovik AC. (2010) A two-step framework for constructing blind image quality indices. IEEE Signal Processing Letters, 17(5): 513-516.

[14] Tang H, Joshi N, Kapoor A. (2011) Learning a blind measure of perceptual image quality, paper presented at Computer Vision and Pattern Recognition (CVPR), 2011 IEEE Conference on, IEEE.

[15] Thuy Tuong Nguyen, Xuan Dai Pham, Dongkyun Kim and Jae Wook Jeon, (2008,"Automatic Exposure Compensation for Line Detection Applications",IEEE International Conference on Multisensor Fusion and Integration for Intelligent SystemsSeoul, Korea.

[16] Pan X, Xie F, Jiang Z, Shi Z, Luo X. (2016) No-reference assessment on haze for remotesensing images. IEEE Geoscience and Remote Sensing Letters, 13(12): 1855-1859.

[17] Daway, H.G.; Mohammed, F.S.; Abdulabbas, D.A. (2016) Aerial Image Enhancement Using Modified Fast Visibility Restoration Based on Sigmoid Function. Adv. Nat. Appl. Sci. 2016, 10 (11), 16-22

[18] He K, Sun J, Tang X. (2011) Single image haze removal using dark channel prior. IEEE transactions on pattern analysis and machine intelligence, 33(12): 2341-2353.

[19] Tan RT. (2008) Visibility in bad weather from a single image, paper presented at Computer Vision and Pattern Recognition, 2008. CVPR 2008. IEEE Conference on, IEEE.

[20] Wang Z, Feng Y. (2014) Fast single haze image enhancement. Computers \& Electrical Engineering, 40(3): 785-795.

[21] Gonzalez RC, Woods RE. (2002) Digital image processing, edited, Prentice hall New Jersey 